\title{
Synergistic induction of CX3CLI by TNF alpha and IFN gamma in osteoblasts from rheumatoid arthritis: involvement of NF-kappa B and STAT- I signaling pathways
}

\author{
Takeo Isozaki \\ Tsuyoshi Kasama \\ Ryo Takahashi \\ Tsuyoshi Odai \\ Kuninobu Wakabayashi \\ Hirohito Kanemitsu \\ Kyoko Nohtomi \\ Hiroko T Takeuchi \\ Satoshi Matsukura \\ Masakazu Tezuka \\ Division of Rheumatology, \\ Department of Internal Medicine, \\ Showa University School of Medicine, \\ Tokyo, Japan, and the Department \\ of Orthopedics, Denencyofu Central \\ Hospital, Tokyo, Japan
}

\begin{abstract}
To explore the regulation of CX3CL1 in inflammatory bone diseases, CX3CL1 expression by osteoblasts (OB) was examined. Human OB isolated from rheumatoid arthritis (RA) patients, osteoarthritis patients, and normal individuals were incubated in the presence of cytokines. Soluble CX3CL1 levels were determined with an enzyme-linked immunosorbent assay. Expression of CX3CL1 mRNA was examined using quantitative real-time polymerase chain reaction. Although tumor necrosis factor (TNF)- $\alpha$ or interferon (IFN)- $\gamma$ alone RA OB induced negligible CX3CL1 secretion, the combination of TNF- $\alpha$ and IFN- $\gamma$ induced dramatic increases in both soluble CX3CL1 protein and mRNA transcripts. This synergistic effect was more pronounced in $\mathrm{OB}$ from RA than in OB from either osteoarthritis or normal individuals. The expression of CX3CL1 was markedly reduced by specific inhibitors of the nuclear factor- $\mathrm{KB}$ $(\mathrm{NF}-\mathrm{\kappa B})$ or STAT-1 transcription factor. These findings suggest that osteoblasts are an important cellular source of CX3CL1 and may play roles in inflammatory bone/joint diseases.
\end{abstract}

Keywords: osteoblast, CX3CL1, chemokine, NF-кB, STAT-1

\section{Introduction}

The pathology of rheumatoid arthritis (RA) is characterized by the infiltration of several inflammatory cell types into the pannus and the joint fluid, followed by tissue destruction. Chemokines and other inflammatory mediators appear to play key roles in the pathogenesis of RA, and the coordinated production of chemokines and proinflammatory cytokines is likely important in the orchestration of the inflammatory response (Kunkel et al 1996; Choy and Panayi 2001). Several cellular components of the joint contribute to the cytokine/chemokine network. Although autoreactive T cells, B cells, and synovial cells (including synovial fibroblasts and macrophages) have crucial roles in pannus formation and arthritis formation, bone-derived cells such as osteoblasts (OBs), osteocytes, and osteoclasts also are recognized as important cellular mediators of bone erosion and destruction in RA (Udagawa et al 2002). Several chemokines are highly expressed in bone erosive lesions (Lisignoli et al 2002). Cells involved in bone formation (eg, OBs) express a variety of chemokines, and OBs appear to be major regulators of bone remolding in both normal and pathological conditions.

During inflammatory processes, OBs exhibit prominent induction of cytokines and chemokines including TNF- $\alpha$, IL-6, IL-8, GRO-alpha, MCP-1, CXCL9, CXCL10, CXCL11, CCL2, ICAM-1, VCAM-1, and angiopoietin-1 (Zhu et al 1994; Takeshita et al 1995; Kurokouchi et al 1998; Lisignoli et al 1999; Kasama et al 2007). Several proinflammatory cytokines such as TNF- $\alpha$, IFN- $\gamma$, IL-6, and transforming growth factor- $\beta$ have been shown to up-regulate the expression of these molecules in
Correspondence:Tsuyoshi Kasama Division of Rheumatology, Department of Internal Medicine, Showa University School of Medicine, I-5-8 Hatanodai, Shinagawa-ku, Tokyo 142-8666, Japan Fax +8I 337848742

Email tkasama@med.showa-u.ac.jp 
osteoblasts. Nevertheless, the exact profile of OB-derived chemokine expression remains unclear.

A member of the chemokine family, CX3CL1 (also known as fractalkine) is synthesized mainly by endothelial cells (ECs) (Bazan et al 1997). The soluble form of CX3CL1 (sCX3CL1) reportedly exerts a chemotactic effect on monocytes, NK cells, and T lymphocytes. sCX3CL1 acts via its receptor, CX3CR1, as an adhesion molecule to promote the firm adhesion of a subset of leukocytes to ECs under conditions of physiological flow (Imai et al 1997; Umehara et al 2001). Thus, CX3CL1 appears to possess immunoregulatory properties that affect inflammatory/immune cell-EC interactions and inflammatory responses. Indeed, numerous studies have implicated CX3CL1 in a variety of inflammatory disorders including glomerulonephritis, systemic sclerosis, and systemic lupus erythematosus (Chen et al 1998; Blaschke et al 2003; Hasegawa et al 2005; Yajima et al 2005). In particular, CX3CL1 may play important roles in RA and rheumatoid vasculitis (Ruth et al 2001; Volin et al 2001; Nanki et al 2002; Matsunawa et al 2006). Although expression of CX3CL1 by OBs was demonstrated recently (Shulby et al 2004), regulatory mechanisms of CX3CL1 in OBs have not yet been elucidated. To further understand the expression and regulation of CX3CL1 in inflammatory bone diseases as well as in physiological conditions, the expression of CX3CL1 by osteoblasts was examined in detail.

\section{Materials and methods}

\section{Reagents}

Complete medium consisted of DMEM (Nissui Pharmaceutical Co., Tokyo, Japan) supplemented with $2 \mathrm{mM} \mathrm{L-glutamine,}$ $100 \mathrm{U} / \mathrm{mL}$ penicillin, $100 \mu \mathrm{g} / \mathrm{mL}$ streptomycin, and $10 \%$ heat-inactivated FBS (Gibco Laboratories, Grand Island, NY). TNF- $\alpha$ and IFN- $\gamma$ were purchased from Genzyme/Techne (Cambridge, MA). The NF-кB p65 small interfering (si)RNA (Silencer NF-kBp65 siRNA), signal transducer and activator of transcription 1 (STAT-1) siRNA (Silencer STAT-1 siRNA), and nonsilencing siRNA (Silencer Negative Control siRNA) were obtained from Ambion (Austin, TX). The NF- $\kappa B$ inhibitor pyrrolidine dithiocarbamate was purchased from Sigma-Aldrich (St. Louis MO). GM-6001, a broadspectrum hydroxamic acid inhibitor of metalloproteases, was purchased from Calbiochem (Darmstadt, Germany). The following inhibitors were all obtained from Sigma Aldrich: PD98059, a mitogen-activated ERK-activated kinase (MEK) 1/2 inhibitor; U73122, a phospholipase C (PLC) inhibitor; wortmannin, a phosphatidylinositol 3'-kinase (PI 3'-kinase) inhibitor; and N,N-dimethylsphingosine, a sphingosine kinase inhibitor.

\section{Preparation of human osteoblasts}

Human OBs were purified from metaphyseal trabecular bones in the proximal femora of RA patients $(n=3)$, osteoarthritis (OA) patients $(n=2)$, and post-traumatic patients (control OBs, $n=2$ ) during total hip arthroplasty, as described previously (Kasama et al 2007). Briefly, after removing pieces of cortical bone, articular cartilage, and soft connective tissue, the fragments were cut into small pieces and incubated with DMEM containing $1 \%$ collagenase at $37{ }^{\circ} \mathrm{C}$ for $30 \mathrm{~min}$, followed by extensive washing. The resultant bone explants were cultured in tissue culture plates in DMEM containing 10\% FBS. When cell monolayers were confluent (after 3-5 weeks of culture), the explants were removed, and the cells were replated at a cell density of $1 \times 10^{5} / \mathrm{mL}$. Cells were incubated for 3 days, then various stimulants were added. Conditioned culture media were collected at selected times thereafter. In some experiments, cell lysates were obtained by the addition of an equal volume of $0.1 \%$ Tween 20 in PBS, followed by incubation for $30 \mathrm{~min}$ on ice. The obtained cells exhibited a flattened polygonal shape with multiple spindlelegs and possessed characteristics of the osteoblast-like phenotype such as osteocalcin expression, bone alkaline phosphatase expression, and mineralization as determined by von Kossa staining (data not shown). Also human osteosarcoma cell line MG63 (from American Type Culture Collection, Manassas, VA) was plated at a cell density of $4.5 \times 10^{5} / \mathrm{cm}^{2}$ in DMEM complete medium, and incubated for $24 \mathrm{~h}$ with the indicated doses of TNF- $\alpha$ $(0.2-20 \mathrm{ng} / \mathrm{mL})$ and/or IFN- $\gamma(1-1000 \mathrm{U} / \mathrm{mL})$.

This study was carried out in accordance with protocols approved by the Human Subjects Research Committee at our institution, and informed consent was obtained from all patients.

\section{Enzyme-linked immunosorbent assay}

Soluble CX3CL1 was quantified using a double ligand enzyme-linked immunosorbent assay (ELISA) that was a modification of an assay described previously (Yajima et al 2005; Matsunawa et al 2006). Monoclonal murine anti-human CX3CL1 (Genzyme/Techne, $4 \mu \mathrm{g} / \mathrm{mL}$ ) was used as the primary antibody $(\mathrm{Ab})$, and the secondary $\mathrm{Ab}$ was biotinylated polyclonal goat anti-CX3CL1 (Genzyme/Techne, $0.25 \mu \mathrm{g} / \mathrm{mL}$ ). This assay detects the chemokine domain of human CX3CL1, and the sensitivity limit is $\sim 150 \mathrm{pg} / \mathrm{mL}$. 


\section{Immunohistochemistry}

Cell-associated CX3CL1 was visualized immunohistochemically by modification of a previously published assay (Kasama et al 2001; Matsunawa et al 2006). Briefly, OBs were grown to near-confluence in an 8-well LabTech chamber slide and then stimulated with cytokines for $24 \mathrm{~h}$. The slides were incubated with polyclonal goat anti-CX3CL1 Ab (R and D systems, Minneapolis, MN) or with pre-immune goat IgG. Biotinylated anti-goat IgG (Nichirei, Japan) and peroxidaseconjugated streptavidin served as second and third reagents, respectively. The optimal color was developed by using a 3,3-diaminobenzidine tetrahydrochloride detection kit (Nichirei, Japan). After rinsing with distilled water, the slides were counterstained with Mayer's hematoxylin.

\section{Flow cytometry}

Flow cytometric analyses of CX3CL1 expression on OBs were carried out as described previously (Yajima et al 2005). OBs were labeled with monoclonal mouse PE-conjugated anti-CX3CL1 Ab (R and D Systems). The fluorescence intensity was measured by a three-color FACScan flow cytometer (Becton Dickinson, Mountain View, CA).

\section{Isolation of total RNA and real-time polymerase chain reaction (PCR)}

Total RNA was extracted from human OBs using TRIzol reagent (Invitrogen, Carlsbad, CA). One-microgram samples of total RNA were reverse transcribed into cDNA by incubation with TaqMan RT reagents (Applied Biosystems, Foster City, CA), first for $120 \mathrm{~min}$ at $37^{\circ} \mathrm{C}$ and then for $10 \mathrm{~min}$ at $25{ }^{\circ} \mathrm{C}$. Real-time PCR was conducted with an ABI Prism ${ }^{\circledR}$ 7900 sequence detection system (Applied Biosystems). The reaction mixture included 40 ng cDNA, which was amplified by AmpliTaq Gold DNA polymerase (Applied Biosystems) as described previously (Kasama et al 2007). For detection of CX3CL1, NF- $\mathrm{kB}$, STAT-1, and ribosomal RNA (rRNA) expression, appropriate Assays-on-Demand ${ }^{\text {TM }}$ primers and probes (Applied Biosystems) were used in the PCR. For quantification, the number of target mRNA copies per rRNA copy was calculated, and values were expressed as -fold increases over control (culture medium alone). In some experiments, the DNA fragments amplified by PCR were subjected to $2 \%$ agarose gel electrophoresis as described previously (Lu et al 2000).

\section{siRNA transfection}

Cells were seeded in 6-well plates at a density of $1.5 \times 10^{5}$ cells per well. Cells were then incubated in complete medium without antibiotics for $24 \mathrm{~h}$ prior to experimentation, at which time they were $60 \%$ to $70 \%$ confluent. Fifty nanomolar siRNA against NF-אB or STAT-1 or nonsilencing siRNA and $10 \mu \mathrm{g} / \mathrm{mL}$ Lipofectamine 2000 (Invitrogen) in $500 \mu \mathrm{L}$ Opti-MEM (Invitrogen) were mixed gently at room temperature for 20 min to allow complexes to form. Thereafter, $1500 \mu \mathrm{L}$ complete medium without antibiotics was added, and the resultant solution was mixed and overlaid on the cells. Cells were incubated with the siRNA/ Lipofectamine 2000 complexes for $24 \mathrm{~h}$ at $37{ }^{\circ} \mathrm{C}$ prior to the isolation of total RNA.

\section{Statistical analysis}

Data are expressed as means \pm SEM and were compared by analysis of variance. The means of groups whose variances were determined to significantly differ were compared using Student's t-test for comparison of the means of multiple groups. Values of $\mathrm{p}<0.05$ were considered significant.

\section{Results}

\section{Secretion and expression of OB-derived $\mathrm{CX} 3 \mathrm{CLI}$ and regulation by TNF- $\alpha$ and IFN- $\gamma$}

We hypothesized that cellular interactions and infiltration are important for the remodeling of bone tissues during pathological as well as physiological conditions and that OBs are an important cellular source of chemotactic factors. To test this hypothesis, we first determined whether OBs isolated from RA patients (RA OBs) could be induced to secrete the chemotactic factor CX3CL1. The effects of the inflammatory cytokine TNF- $\alpha$ and the immunoregulatory cytokine IFN- $\gamma$ on CX3CL1 secretion were examined.

Neither TNF- $\alpha(20 \mathrm{ng} / \mathrm{mL})$ nor IFN- $\gamma(1000$ units $/ \mathrm{mL})$ significantly affected CX3CL1 secretion from RA OBs as compared with medium alone (Figure 1a). On the other hand, when applied together, graded doses of either TNF- $\alpha$ or IFN- $\gamma$ with IFN- $\gamma$ or TNF- $\alpha$, respectively, induced significant dosedependent secretion of CX3CL1 from RA OBs (medium, $375.4 \mathrm{pg} / \mathrm{mL}$; TNF- $\alpha+$ IFN- $\gamma, 5681.7 \mathrm{pg} / \mathrm{mL}$; Figure 1a). A similar pattern of CX3CL1 secretion was observed in the human osteosarcoma cell line MG63 (Figure 1b).

CX3CL1 from RA OBs stimulated with both cytokines was detectable in culture supernatants at $8 \mathrm{~h}$, and levels were increased sharply at $24 \mathrm{~h}$. Levels of cellassociated CX3CL1 were greater than levels of CX3CL1 in the supernatants until after $8 \mathrm{~h}$ (Figure 1c). Because membrane-bound CX3CL1 is cleaved to the soluble form 
by metalloproteases such as ADAM17 and ADAM10 (Garton et al 2001, Hundhausen et al 2003), the involvement of proteases in the generation of $\mathrm{sCX} 3 \mathrm{CL} 1$ was examined in this in vitro culture system. GM-6001, a broad-spectrum inhibitor of metalloproteases, was added to $\mathrm{OB}$ cultures, and CX3CL1 in culture supernatants and cell lysates was assessed by ELISA. As shown in Figure 1d, GM-6001 significantly inhibited CX3CL1 levels in supernatants of OBs stimulated with both cytokines in combination. While, a modest increase in cell-associated CX3CL1 was observed by treatment with GM-6001 on cytokine-stimulated OBs compared with no compounds, but this was not statistically significant. Therefore, GM6001-sensitive metalloproteases may be, in part, involved in CX3CL1 cleavage in cytokine-stimulated OBs.

The cell-surface expression of CX3CL1 was also examined immunohistochemically (Figure 2a). Although small amounts of CX3CL1 antigen were detected in unstimulated RA OBs and in OBs stimulated with each cytokine alone (data not shown), substantially increased amounts of CX3CL1 were observed in OBs stimulated with the combination of cytokines (Figure 2a). Furthermore, membrane-bound CX3CL1 protein in RA OBs was examined using flow cytometric analysis. As observed by ELISA and immunohistochemistry, combined stimulation with TNF- $\alpha$ and IFN- $\gamma$ induced enhanced expression of membrane-bound CX3CL1 on RA OBs (Figure 2b). To determine whether increased CX3CL1 antigen levels are accompanied by similarly increased CX3CL1 mRNA transcript levels, we examined the expression of OB-derived CX3CL1 mRNA with real-time PCR. As shown in Figure 2c, the expression of CX3CL1 mRNA in OBs was significantly enhanced by both TNF- $\alpha$ and IFN- $\gamma$ compared with culture medium or with either cytokine alone. This augmented expression of
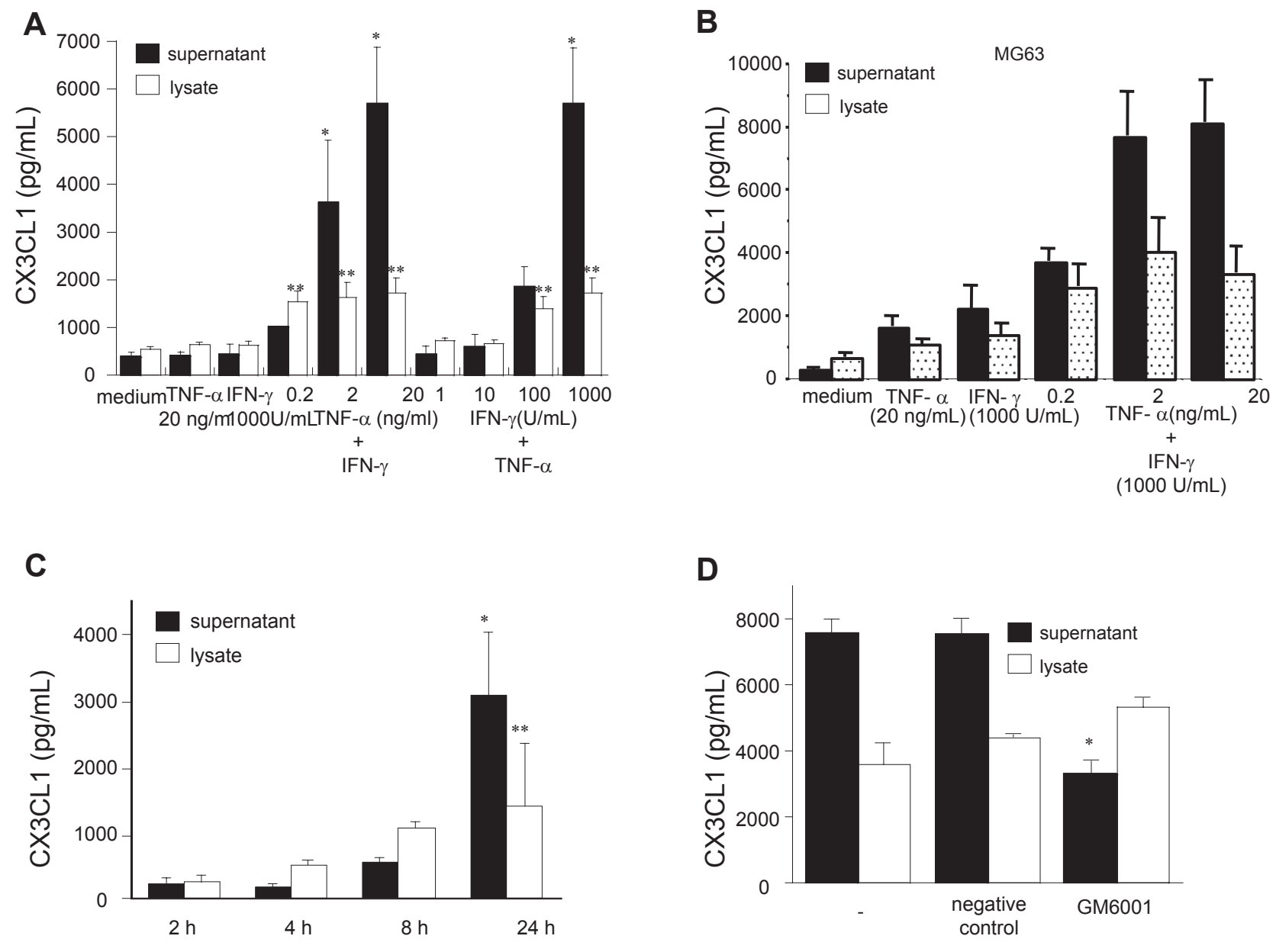

Figure I Secretion of CX3CLI from OBs and the effects of TNF- $\alpha$ and IFN- $\gamma$. Cultured OBs from RA patients (A) or MG63 cells (B) were incubated for $24 \mathrm{~h}$ with the indicated doses of TNF- $\alpha$ and/or IFN- $\gamma$. (C) RA OBs stimulated with cytokines were collected after 2, 4, 8, and 24 h of stimulation. (D) RA OBs stimulated with cytokines were treated with either GM-600 I or negative control compound for $24 \mathrm{~h}$. CX3CLI levels in culture supernatants and cell lysates were assayed using specific ELISAs. Data are expressed as the means \pm SEM of 5 independent experiments. ${ }^{p} \mathrm{p}<0.01$ vs control medium; ${ }^{* *} \mathrm{p}<0.05$ vs control medium. 
CX3CL1 mRNA was confirmed by agarose-gel analysis of PCR products (Figure $2 \mathrm{~d}$ ).

Next, the levels of CX3CL1 secretion were compared among OBs from patients with an inflammatory disease (RA), patients with a non-inflammatory disease (OA), and normal individuals. In response to the combination of TNF- $\alpha$ and IFN- $\gamma$, a significantly increased amount of CX3CL1 was secreted into the supernatant by RA and OA OBs compared with normal OBs (Figure 3a). Although there appeared to be an obvious difference in CX3CL1 secretion between RA OBs and OA OBs (4629.3 pg/ml vs $3263.5 \mathrm{pg} / \mathrm{mL})$, the result did not reach statistical significance. However, enhanced CX3CL1 mRNA expression was observed in RA OBs stimulated with the combination of cytokines compared with both normal and OA OBs $(\mathrm{p}<0.05)$ (Figure $3 b)$. In addition, receptor expression for either TNF- $\alpha$ or IFN- $\gamma$ was examined on OBs from either RA patients or OA patients, controls, because these results demonstrated that CX3CL1 expression from RA, OA or controls was differentially regulated by TNF- $\alpha /$ IFN- $\gamma$. However, there were no significant differences in their expression between RA, OA patients and controls by flow cytometry and RT-PCR.

\section{NF- $\kappa B$ expression and its role in the cytokine-mediated induction of $\mathrm{CX} 3 \mathrm{CL}$ lin OBs}

To further examine the mechanisms of CX3CL1 induction in OBs, the expression of NF- $\kappa B$ mRNA in OBs was examined. Although the expression of NF- $\mathrm{KB}$ mRNA was induced by stimulation with either TNF- $\alpha$ or IFN- $\gamma$, together the two cytokines elicited an 8.4-fold increase in NF- $\kappa$ B levels within $4 \mathrm{~h}$ (Figure $4 \mathrm{a}$ ). The potential role of $\mathrm{NF}-\kappa \mathrm{B}$ in the induction of CX3CL1 expression was investigated by evaluating the capacity of anti-NF- $\mathrm{KB}$ siRNA to inhibit CX3CL1 expression
A Immunochemistry

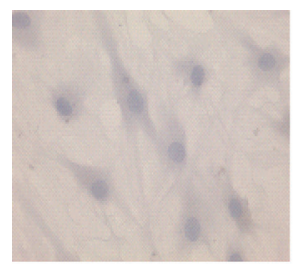

control lgG

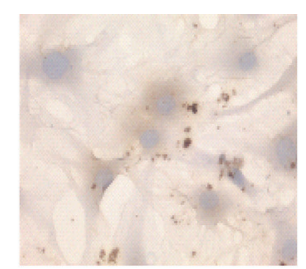

anti-CX3CL1 IgG

\section{Real time RT-PCR}

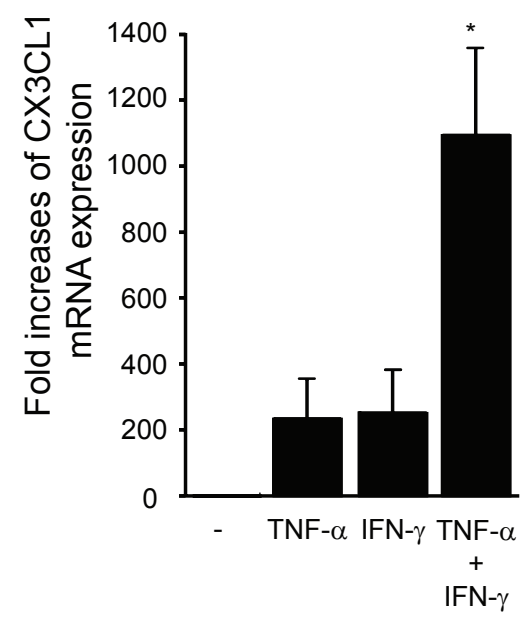

B

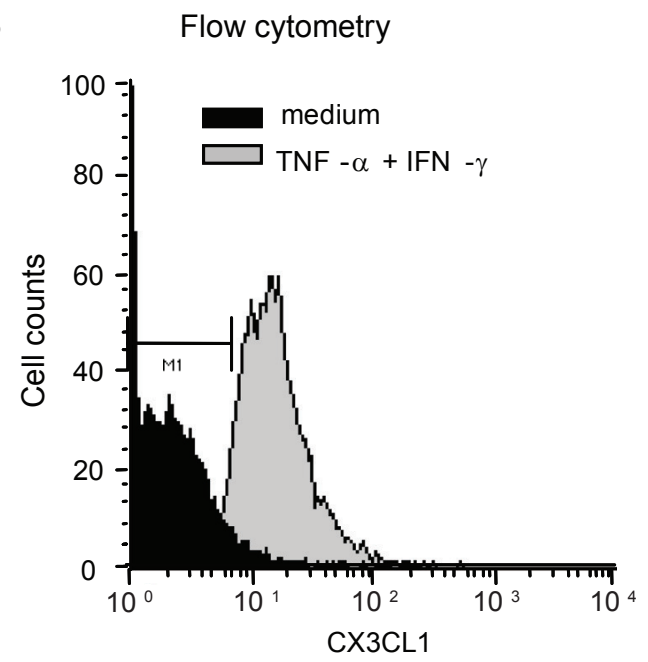

D

\section{Semiquantitative RT-PCR}

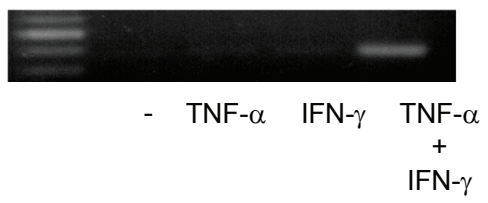

$388 \mathrm{bp}$

$\mathrm{FN}-\gamma$

Figure 2 Cell surface expression and mRNA expression of CX3CLI in RA OBs. (A) Representative photomicrographs showing the immunohistochemical localization of antigenic CX3CLI in RA OBs stimulated with TNF- $\alpha(20 \mathrm{ng} / \mathrm{mL})$ and IFN- $\gamma(1000 \mathrm{U} / \mathrm{mL})$ for $24 \mathrm{~h}$ (original magnification, 400×). (B) Flow cytometric analysis of the level of CXC3LI expression. Cultured OBs from RA patients were incubated for $24 \mathrm{~h}$ with TNF- $\alpha(20 \mathrm{ng} / \mathrm{mL})$ and IFN- $\gamma(\mathrm{I} 000 \mathrm{U} / \mathrm{mL})$. (C) Real-time RT-PCR analysis of CX3CLI mRNA expression in RA OBs. Cultured OBs from RA patients were incubated for $4 \mathrm{~h}$ with TNF- $\alpha(20 \mathrm{ng} / \mathrm{mL})$ and IFN- $\gamma($ I $000 \mathrm{U} / \mathrm{mL})$. Data are means \pm SEM of 3 independent experiments. ${ }^{*} \mathrm{P}<0.05$ vs control medium. (D) Representative agarose gel analysis of CX3CLI semiquantitative RT-PCR products. 
A

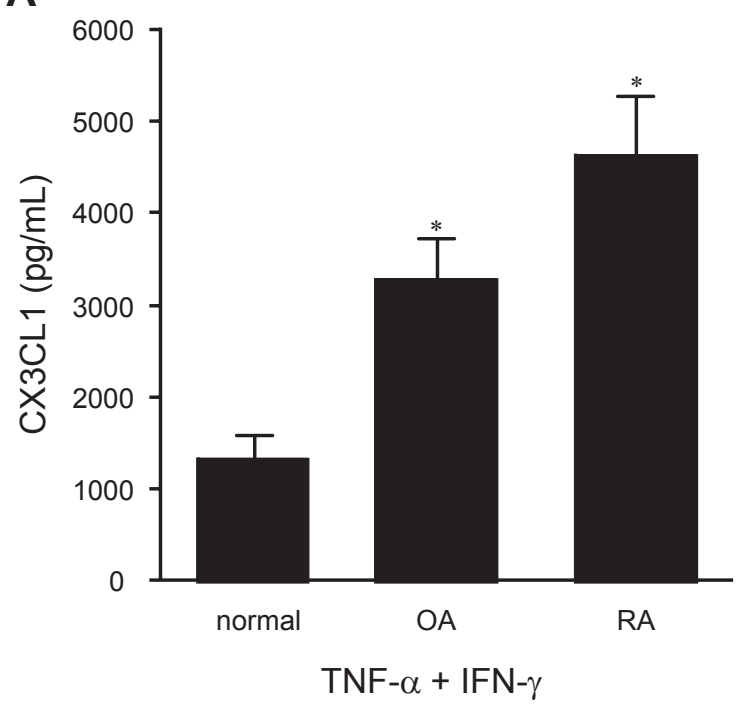

B

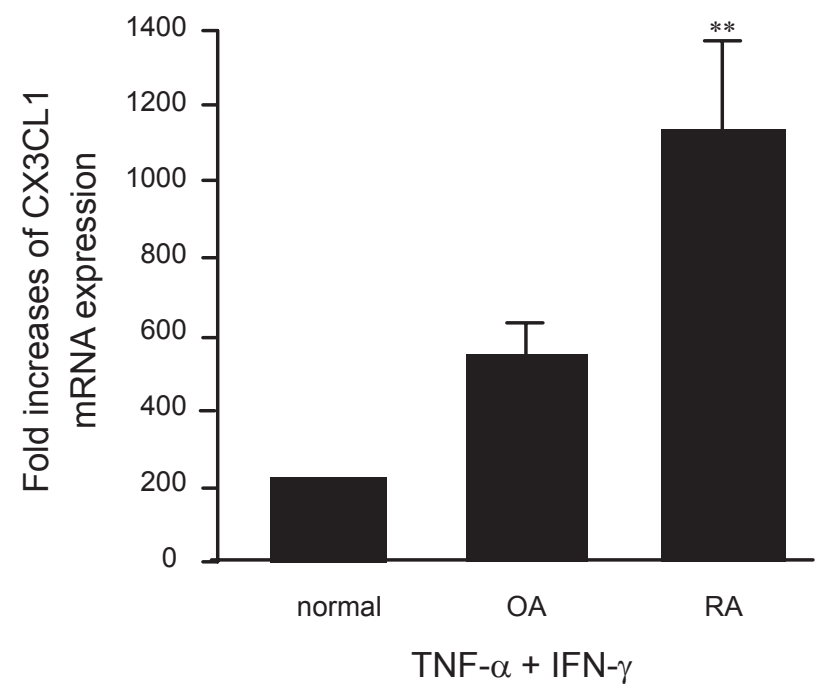

Figure 3 Secretion $(\mathbf{A})$ and mRNA expression $(\mathbf{B})$ of $C X 3 C L I$ by OBs from $R A, O A$, or normal controls. OBs from $R A$ patients $(n=3)$, OA patients $(n=2)$, or normal individuals $(\mathrm{n}=2)$ were incubated for $24 \mathrm{~h}$ or $4 \mathrm{~h}$ with TNF- $\alpha(20 \mathrm{ng} / \mathrm{mL})$ and IFN- $\gamma(1000 \mathrm{U} / \mathrm{mL})$. CX3CLI levels in the culture supernatants $(\mathbf{A})$ and CX3CLI mRNA expression (B) were assayed using specific ELISAs and real-time PCR, respectively. Data are expressed as the means \pm SEM of 3 to 5 independent experiments. ${ }^{*}<0.05$ vs control OBs, ${ }^{*} \mathrm{p}<0.05$ vs control OBs and $\mathrm{OA}$ OBs.

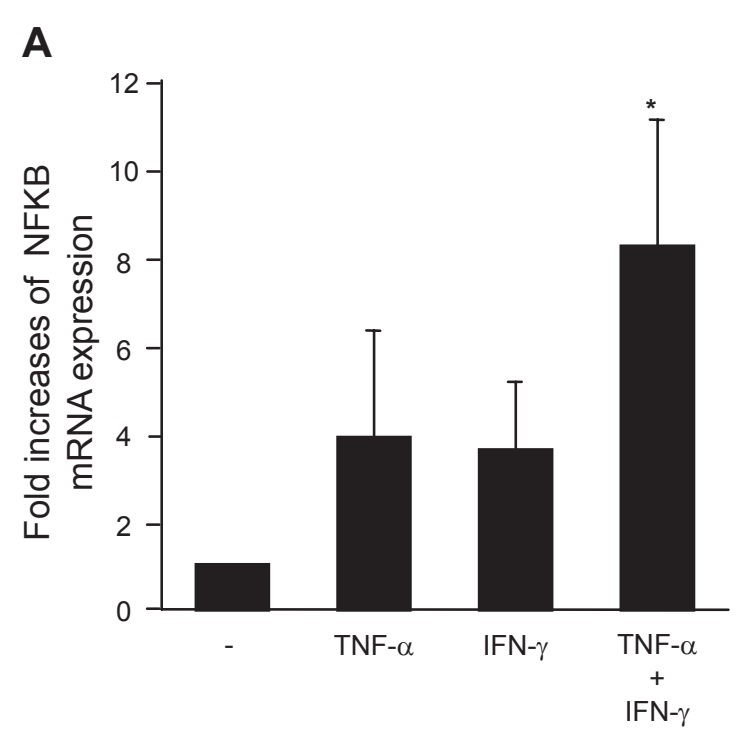

B

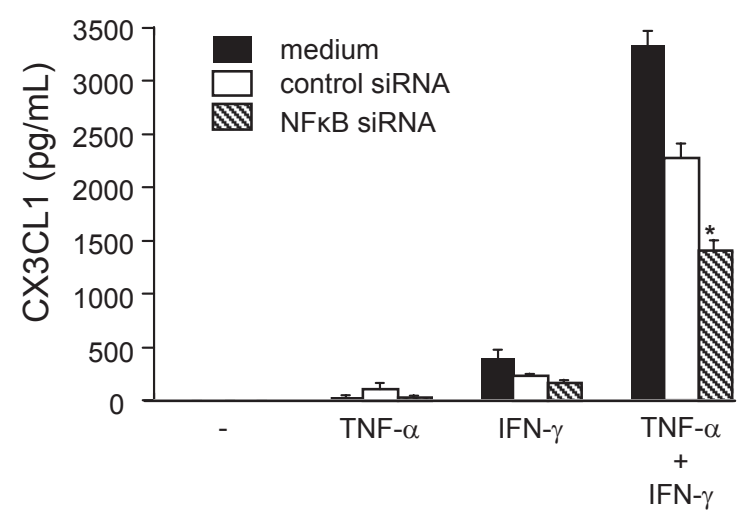

C

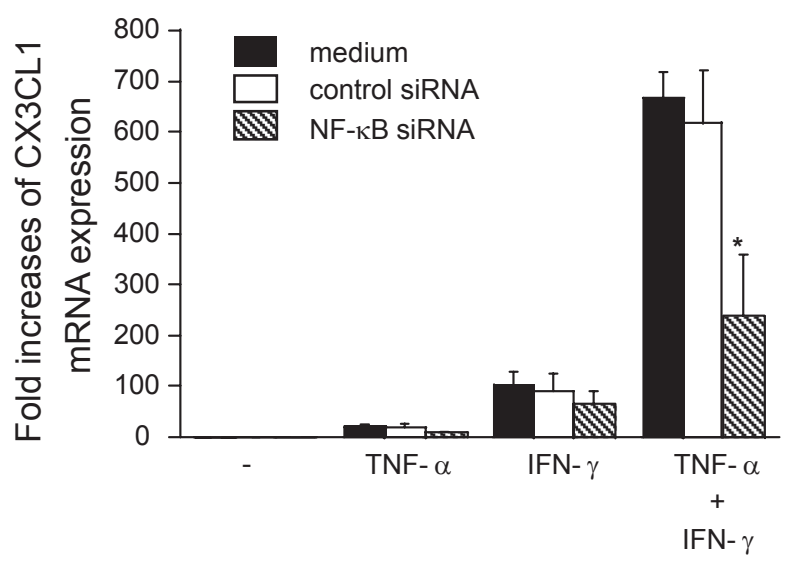

Figure 4 NF- $\kappa B$ expression in OBs and its role in the induction of $C X 3 C L I$ expression. (A) Real-time RT-PCR analysis revealed enhanced expression of NF- $\kappa B$ mRNA in RA OBs incubated for $4 \mathrm{~h}$ with TNF- $\alpha(20 \mathrm{ng} / \mathrm{mL})$ plus IFN- $\gamma(1000 \mathrm{U} / \mathrm{mL})$. (B and C) Effects of NF-kB-specific siRNA on CX3CLI secretion and $\mathrm{mRNA}$ expression. RA OBs transfected with either NF- $\kappa B$-specific siRNA or negative control siRNA were incubated for $24 \mathrm{~h}(\mathbf{B})$ or $4 \mathrm{~h}(\mathrm{C})$ with TNF- $\alpha(20 \mathrm{ng} / \mathrm{mL}) \mathrm{plus} \mathrm{IFN-} \gamma(\mathrm{I000} \mathrm{U} / \mathrm{mL})$, after which culture supernatants $(\mathbf{B})$ or total RNA $(\mathbf{C})$ were isolated and ELISA or real-time PCR for CX3CLI were conducted. Data are means \pm SEM from 3 independent experiments. ${ }^{*} \mathrm{P}<0.05$ vs medium alone (A), ${ }^{*} \mathrm{p}<0.05$ vs TNF- $\alpha / \mathrm{IFN}-\gamma$ with control siRNA (B and $\mathbf{C}$ ). 
in OBs. Whereas addition of control siRNA had no specific effect on the induction of CX3CL1 expression by costimulation with TNF- $\alpha$ and IFN- $\gamma$, the addition of siRNA targeted to $\mathrm{NF}-\kappa \mathrm{B}$ significantly reduced the synergistic effect of TNF- $\alpha$ and IFN- $\gamma$ on CX3CL1 expression at both the protein $(38.5 \%$ suppression compared with control siRNA; Figure 4b) and mRNA (61.7\% suppression; Figure 4c) levels.

In addition, the effect of pyrrolidine, an NF- $\kappa \mathrm{B}$ inhibitor, on CX3CL1 expression by OBs was examined. Consistent with the siRNA inhibition, both the secretion (Figure $5 a)$ and mRNA expression (Figure 5b) of CX3CL1 by cytokine-stimulated RA OBs were significantly inhibited by pyrrolidine. To investigate other second messengers involved in the induction of CX3CL1 expression by cytokines, different kinase and transcription factor inhibitors were added to $\mathrm{OB}$ cultures. In contrast to pyrrolidine, inhibitors of MEK1/2 (PD98059; $50 \mu \mathrm{mol} / \mathrm{L}$ ), PLC (U73122; $1 \mu \mathrm{mol} / \mathrm{L}$ ), PI 3 '-kinase (wortmannin; $30 \mathrm{nmol} / \mathrm{L}$ ), and sphingosine kinase (N,N-dimethylsphingosine; $5 \mu \mathrm{mol} / \mathrm{L}$ ) did not affect CXCL1 expression (data not shown).

\section{STAT- I expression in OBs}

\section{and its involvement in CX3CLI expression}

The present results indicate the importance of IFN- $\gamma$ and TNF- $\alpha$ in CX3CL1 expression by OBs. To further explore the regulatory mechanisms underlying CX3CL1 expression, we examined the role of STAT-1 in this induction. Although the expression of STAT-1 in RA OBs was not induced by TNF- $\alpha$ alone, mRNA expression of STAT-1 was up-regulated by the combination of IFN- $\gamma$ with TNF- $\alpha$ and, to a lesser extent, by IFN- $\gamma$ alone (Figure 6a). Next, siRNA against STAT-1 was transfected into RA OBs, and the mRNA expression and secretion of CX3CL-1 were examined. The up-regulated mRNA expression and secretion of CX3CL1 in OBs stimulated by the combination of cytokines were significantly inhibited by siRNA targeted to STAT-1, reducing the levels of secreted protein $69.8 \%$ (Figure $6 \mathrm{~b}$ ) and of mRNA expression $47.7 \%$ (Figure. 6c) compared with control siRNA.

\section{Discussion}

The present study clearly demonstrates that OBs from patients with an inflammatory condition (RA) and even a non-inflammatory condition (OA) are a prominent cellular source of CX3CL1 in response to the combination of TNF- $\alpha$ and IFN- $\gamma$. Although it was demonstrated previously that CX3CL1 is expressed by OBs in vitro (Shulby et al 2004), the present report examined the regulatory mechanisms of CX3CL1 expression by OBs. Immunohistochemistry and flow cytometry experiments revealed increased amounts of intracellular CX3CL1 and membrane expression upon stimulation with TNF- $\alpha$ and IFN- $\gamma$. Furthermore, CX3CL1 transcripts detected by real-time RT-PCR were promptly upregulated by cytokine stimulation. $\mathrm{CX} 3 \mathrm{CL} 1$ protein levels in cell lysates reached maximal levels $8 \mathrm{~h}$ after co-stimulation with TNF- $\alpha$ and IFN- $\gamma$ and decreased thereafter, whereas CX3CL1 levels in supernatants increased gradually between
A

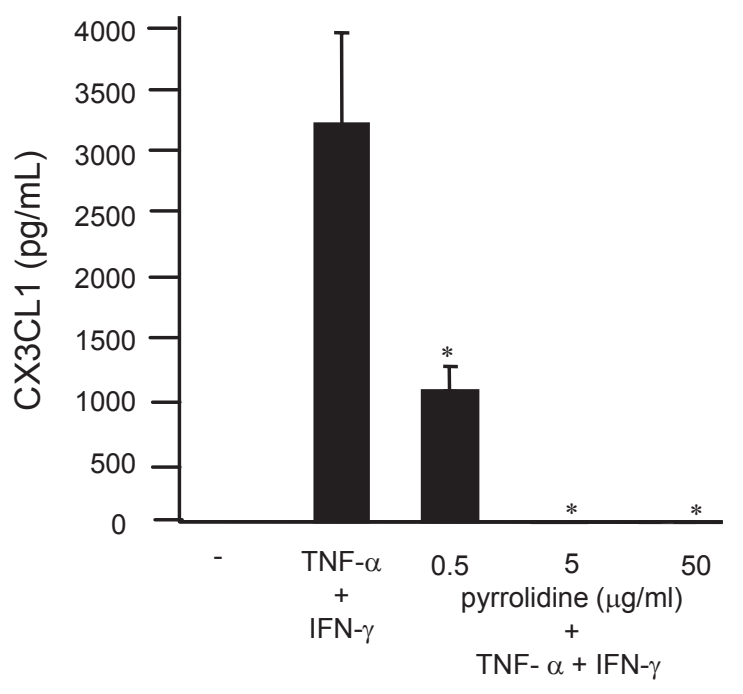

B

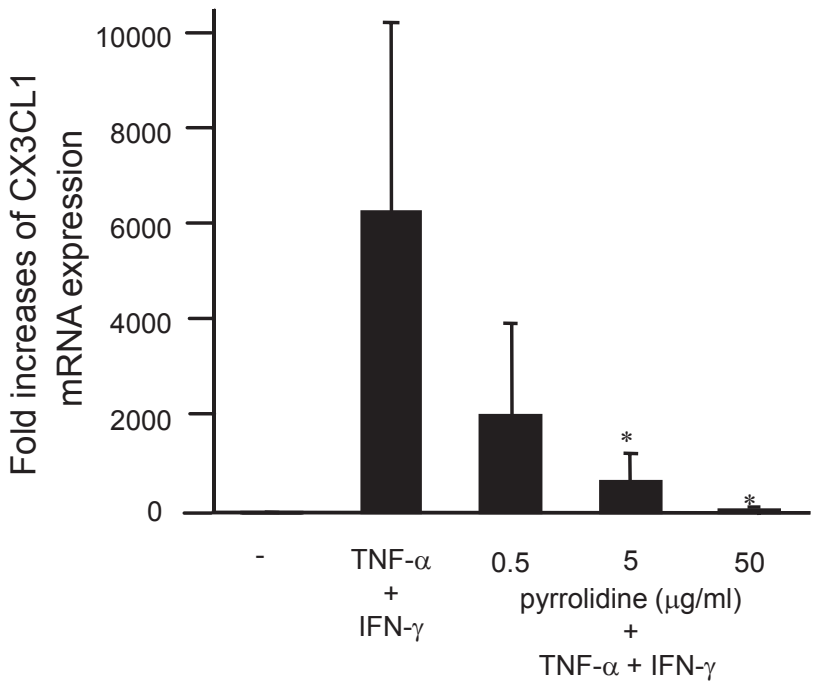

Figure 5 Effect of pyrrolidine, an NF- $\kappa B$ inhibitor, on CX3CLI expression by OBs. RA OBs stimulated with TNF- $\alpha / I F N-\gamma$ were incubated with graded doses of the NF- $\kappa B$ inhibitor pyrrolidine, after which culture supernatants $(\mathbf{A})$ or total RNA (B) was isolated and ELISA or real-time PCR for CX3CLI were conducted. Data are means \pm SEM from three independent experiments. ${ }^{\mathrm{p}}<0.05$ vs TNF- $\alpha / \mathrm{IFN}-\gamma$. 
A

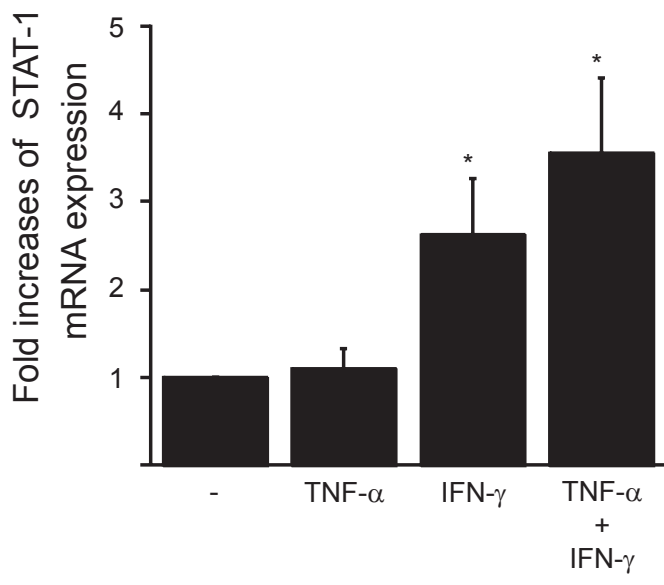

B
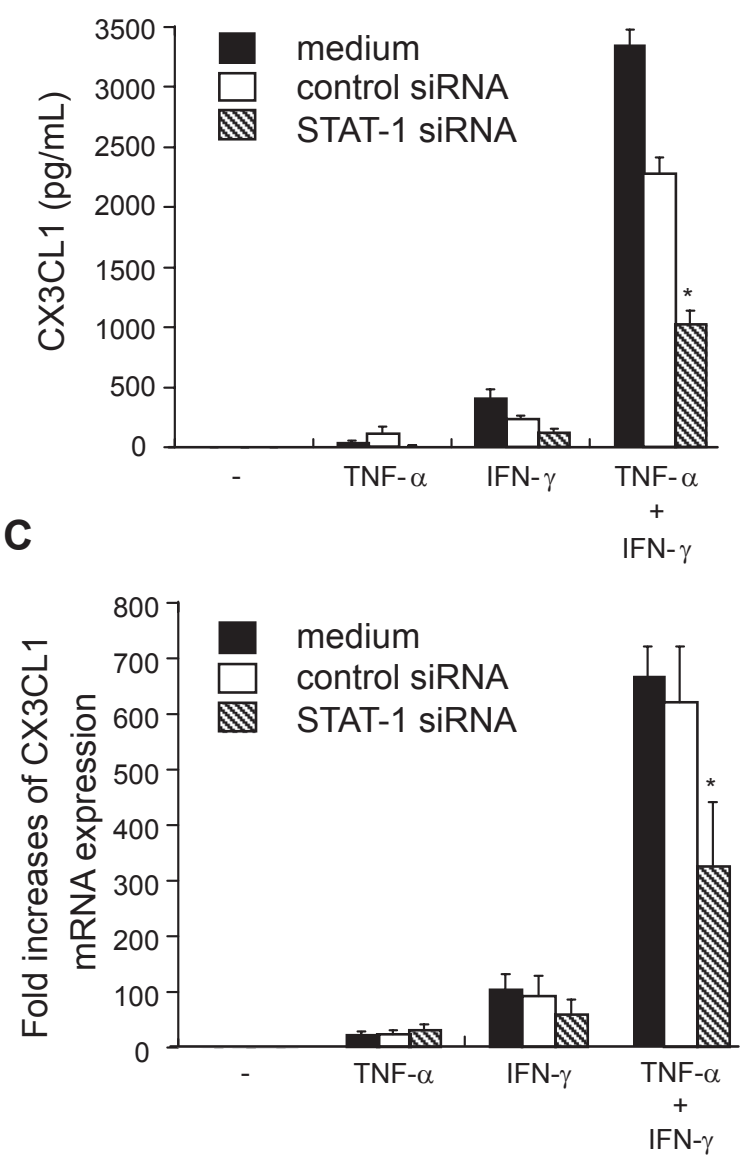

Figure 6 STAT-I expression in OBs and its role in the induction of CX3CLI expression. (A) Real-time RT-PCR analysis revealed enhanced expression of STAT-I mRNA in RA OBs incubated for $4 \mathrm{~h}$ with TNF- $\alpha(20 \mathrm{ng} / \mathrm{mL})$ plus IFN- $\gamma(1000 \mathrm{U} / \mathrm{mL})$ and in RA OBs incubated with IFN- $\gamma$ alone. (B and C) Effects of STAT-I-specific siRNA on CX3CLI secretion and expression. RA OBs transfected with either STAT-I-specific siRNA or negative control siRNA were incubated for $24 \mathrm{~h}$ (B) or $4 \mathrm{~h}(\mathrm{C})$ with TNF- $\alpha$ (20 $\mathrm{ng} / \mathrm{mL})$ plus IFN- $\gamma(1000 \mathrm{U} / \mathrm{mL})$, after which culture supernatants $(\mathbf{B})$ or total RNA (C) was isolated and ELISA or real-time PCR for CX3CLI was conducted. Data are means \pm SEM from three independent experiments. ${ }^{\circ} \mathrm{p}<0.05$ vs medium alone $(\mathbf{A}),{ }^{*} \mathrm{p}<0.05$ vs TNF- $\alpha /$ IFN- $\gamma$ with control siRNA (B and $\left.\mathbf{C}\right)$.

2 and $24 \mathrm{~h}$ after cytokine stimulation. Also metalloproteases such as ADAM10 and ADAM17 (Garton et al 2001; Hundhausen et al 2003) appear to be important for cleaving membranebound CX3CL1 into the soluble form. Consistent with these previous reports, GM-6001-sensitive metalloproteases may be, in part, involved in CX3CL1 cleavage in cytokinestimulated OBs.

We have shown that OBs from patients with RA have an enhanced capacity to express CX3CL1 compared with OBs from patients with a non-inflammatory condition (OA) or OBs from normal individuals. Previous studies have shown that RA OBs produce greater amounts of chemokines such as CXCL1 and CCL2 under unstimulated conditions or inflammatory stimuli (including IFN- $\gamma$ ) than do OA OBs (Lisignoli et al 1999, 2002). It has been well documented that TNF- $\alpha$ and IFN- $\gamma$ cooperate in a variety of biological responses and synergistically enhance the expression of genes involved in immune and inflammatory responses (Paludan 2000). Synergistic cytokine induction can be envisaged in chronic inflammatory reactions such as RA, during which inflammatory or immunoregulatory cytokines, including TNF- $\alpha$ and IFN- $\gamma$, are very likely to be present (van Roon et al 1995; Klimiuk et al 1997).

Blaschke et al have shown that CX3CL1 markedly induces the secretion of matrix metalloprotease-2 (MMP-2) from synovial fibroblasts (Blaschke et al 2003), in addition to its other known functions as a chemoattractant of T cells, NK cells, and macrophages; an adhesion molecule; and an inducer of angiogenesis (Bazan et al 1997; Volin et al 2001; Ruth et al 2001; Ancuta et al 2003). Induction of the MMP family plays a crucial role in the bone/joint destruction observed in RA (Tak and Bresnihan 2000). In addition, osteoblasts not only play a central role in bone formation by synthesizing multiple bone matrix proteins, but regulate 
osteoclast maturation by soluble factors and cognate interaction, resulting in bone resorption. To further clarify the function of OG-derived CX3CL1, we tried to explore the biological significance of CX3CL1 in osteoclast formation. First, recombinamt CX3CL1 was added to human peripheral blood monocytes derived osteoclasts, which were stimulated to maturate by GM-CSF and RANKL (Shinoda et al 2003). Second, human peripheral blood monocytes were added onto osteogenic cells stimulated by cytokine (TNF- $\alpha$ plus IFN- $\gamma$ ), and then stimulated by GM-CSF and RANKL. However, we could not determine any significant effects (inhibition or stimulation) of recombinant CX3CL1 or cell-bound CX3CL1 on osteoclast formation or maturation (unpublished observation). CX3CL1, especially the soluble form, may have important functions at inflammatory sites, and these functions may depend upon the type of stimuli or upon other factors including the type of activated cells, damaged organ, or bone/joint inflammation.

Notably, several investigations have demonstrated that co-stimulation by TNF- $\alpha$ and IFN- $\gamma$ stimulates CX3CL1 expression by various cell types (Yoshida et al 2001; Ludwig et al 2002). However, until now the signaling mechanisms by which inflammatory stimuli induce CX3CL1 expression by $\mathrm{OBs}$ had not been elucidated. Our findings revealed that co-stimulation by TNF- $\alpha$ and IFN- $\gamma$ induces CX3CL1 expression by OBs mainly through the activation of NF- $\mathrm{KB}$ and STAT-1 pathways. It is well known that TNF- $\alpha$ and $\mathrm{NF}-\kappa \mathrm{B}$ are important for the induction and expression of cytokines, chemokines, and growth factors (Li and Verma 2002; Bonizzi and Karin 2004; Jimi and Ghosh 2005) and play crucial roles in the pathogenesis of RA (Aggarwal 2000). Indeed, several cell types express CX3CL1 through the NF- $\kappa$ B pathway upon stimulation by TNF- $\alpha$ (Garcia et al 2000; Chandrasekar et al 2003; Chen et al 2003; Ahn et al 2004). Because CX3CL1 induction seems to be independent of the MEK, PLC, sphingosine kinase, and PI 3'-kinase pathways, TNF- $\alpha$ signaling through NF- $\kappa \mathrm{B}$ may be crucial for the expression of CX3CL1 by OBs. Furthermore, the activity of the NF- $\mathrm{KB}$ pathway may vary depending on cell type and on the factors induced by TNF- $\alpha$.

The present study also investigated the role of the transcription factor STAT-1 in CX3CL1 expression by OBs. STAT-1 expression by OBs was up-regulated by IFN- $\gamma$ stimulation and by the combination of TNF- $\alpha$ and IFN- $\gamma$, but not by TNF- $\alpha$ alone. siRNA inhibition of STAT-1 demonstrated that STAT-1 appears to be important for up-regulating CX3CL1 in OBs. STAT-1 plays crucial roles in several inflammatory conditions including RA (Wang et al 1995;
Kasperkovitz et al 2004), as well as in bone remodeling (Kim et al 2003; Takayanagi et al 2005). The present results suggest that STAT-1 regulation of CX3CL1 expression by OBs may be important in these situations.

In conclusion, OBs appear to be an important cellular source of CX3CL1. A more complete understanding of the functions of OB-derived CX3CL1 in pathological conditions such as RA should provide insights into inflammatory disease pathogenesis and suggest new strategies for clinical intervention.

\section{Abbreviations}

ELISA, enzyme-linked immunosorbent assay; OBs, osteoblasts; IFN- $\gamma$, interferon- $\gamma$; NF-kB, nuclear factor-kappaB; OA, osteoarthritis; PCR, polymerase chain reaction; RA, rheumatoid arthritis; siRNA, small interfering RNA; TNF- $\alpha$, tumor necrosis factor- $\alpha$.

\section{Acknowledgments}

This study was supported, in part, by the grant of Ministry of Health, Labor and Welfare of Japan.

\section{Disclosures}

The authors have no conflicts of interest to disclose.

\section{References}

Aggarwal BB. 2000. Tumour necrosis factors receptor associated signalling molecules and their role in activation of apoptosis, JNK and NF-kappaB. Ann Rheum Dis, 59(Suppl 1):i6-16.

Ahn SY, Cho CH, Park KG, et al. 2004. Tumor necrosis factor-alpha induces fractalkine expression preferentially in arterial endothelial cells and mithramycin A suppresses TNF-alpha-induced fractalkine expression. Am J Pathol, 164:1663-72.

Ancuta P, Rao R, Moses A, et al. 2003. Fractalkine preferentially mediates arrest and migration of CD16+ monocytes. J Exp Med, 197:1701-7.

Bazan JF, Bacon KB, Hardiman G, et al. 1997. A new class of membranebound chemokine with a CX3C motif. Nature, 385:640-4.

Blaschke S, Koziolek M, Schwarz A, et al. 2003. Proinflammatory role of fractalkine (CX3CL1) in rheumatoid arthritis. J Rheumatol, 30:1918-27.

Bonizzi G and Karin M. 2004. The two NF-kappaB activation pathways and their role in innate and adaptive immunity. Trends Immunol, $25: 280-8$

Chandrasekar B, Mummidi S, Perla RP, et al. 2003. Fractalkine (CX3CL1) stimulated by nuclear factor kappaB (NF-kappaB)-dependent inflammatory signals induces aortic smooth muscle cell proliferation through an autocrine pathway. Biochem J, 373:547-58.

Chen $\mathrm{S}$, Bacon KB, Li L, et al. 1998. In vivo inhibition of $\mathrm{CC}$ and CX3C chemokine-induced leukocyte infiltration and attenuation of glomerulonephritis in Wistar-Kyoto (WKY) rats by vMIP-II. $J$ Exp Med, 188:193-8.

Chen YM, Tu CJ, Hung KY, et al. 2003. Inhibition by pentoxifylline of TNF-alpha-stimulated fractalkine production in vascular smooth muscle cells: evidence for mediation by NF-kappa B down-regulation. $\mathrm{Br} \mathrm{J}$ Pharmacol, 138:950-8.

Choy EHS and Panayi GS. 2001. Cytokine pathways and joint inflammation in rheumatoid arthritis. $N$ Engl J Med, 344:907-16. 
Garcia GE, Xia Y, Chen S, et al. 2000. NF-kappaB-dependent fractalkine induction in rat aortic endothelial cells stimulated by IL-1beta, TNFalpha, and LPS. J Leukocyte Biol, 67:577-84.

Garton KJ, Gough PJ, Blobel CP, et al. 2001. Tumor necrosis factor-aconverting enzyme (ADAM17) mediates the cleavage and shedding of fractalkine (CX3CL1). J Biol Chem, 276:37993-8001.

Hasegawa M, Sato S, Echigo T, et al. 2005. Up regulated expression of fractalkine/CX3CL1 and CX3CR1 in patients with systemic sclerosis. Ann Rheum Dis, 64:21-8.

Hundhausen C, Misztela D, Berkhout TA, et al. 2003. The disintegrin-like metalloproteinase ADAM10 is involved in constitutive cleavage of CX3CL1 (fractalkine) and regulates CX3CL1-mediated cell-cell adhesion. Blood, 102:1186-95.

Imai T, Hieshima K, Haskell C, et al. 1997. Identification and molecular characterization of fractalkine receptor CX3CR1, which mediates both leukocyte migration and adhesion. Cell, 91:521-30.

Jimi E and Ghosh S. 2005. Role of nuclear factor-kappaB in the immune system and bone. Immunol Rev, 208:80-7.

Kasama T, Isozaki T, Odai T, et al. 2007. Expression of angiopoietin-1 in osteoblasts and its inhibition by tumor necrosis factor-alpha and interferon-gamma. Transl Res, 149:265-73.

Kasama T, Shiozawa F, Kobayashi K, et al. 2001. Vascular endothelial growth factor expression by activated synovial leukocytes in rheumatoid arthritis. Critical involvement of the interaction with synovial fibroblasts. Arthritis Rheum, 44:2512-24.

Kasperkovitz PV, Verbeet NL, Smeets TJ, et al. 2004. Activation of the STAT1 pathway in rheumatoid arthritis. Ann Rheum Dis, 63:233-9.

Kim S, Koga T, Isobe M, et al. 2003. Stat1 functions as a cytoplasmic attenuator of Runx2 in the transcriptional program of osteoblast differentiation. Genes Dev, 17:1979-91.

Klimiuk PA, Goronzy JJ, Bjor nsson J, et al. 1997. Tissue cytokine patterns distinguish variants of rheumatoid synovitis. Am J Pathol, 151:1311-9.

Kunkel SL, Lukacs NW, Kasama T, et al. 1996. The role of chemokines in inflammatory joint disease. J Leukocyte Biol, 58:6-12.

Kurokouchi K, Kambe F, Yasukawa K, et al. 1998. TNF-alpha increases expression of IL-6 and ICAM-1 genes through activation of NF-kappaB in osteoblast-like ROS17/2.8 cells. J Bone Miner Res, 13:1290-9.

Li Q and Verma IM. 2002. NF-kappaB regulation in the immune system. Nat Rev Immunol, 2:725-34.

Lisignoli G, Toneguzzi S, Grassi F, et al. 2002. Different chemokines are expressed in human arthritic bone biopsies: IFN-gamma and IL-6 differently modulate IL-8, MCP-1 and rantes production by arthritic osteoblasts. Cytokine, 20:231-8.

Lisignoli G, Toneguzzi S, Pozzi C, et al. 1999. Proinflammatory cytokines and chemokine production and expression by human osteoblasts isolated from patients with rheumatoid arthritis and osteoarthritis. J Rheumatol, 26:791-9.

Lu J, Kasama T, Kobayashi K, et al. 2000. Vascular endothelial growth factor expression and regulation of murine collagen-induced arthritis. J Immunol, 164:5922-7.

Ludwig A, Berkhout T, Moores K, et al. 2002. Fractalkine is expressed by smooth muscle cells in response to IFN-gamma and TNF-alpha and is modulated by metalloproteinase activity. J Immunol, 168:604-12.
Matsunawa M, Isozaki T, Odai T, et al. 2006. Increased serum levels of soluble fractalkine (CX3CL1) correlate with disease activity in rheumatoid vasculitis. Arthritis Rheum, 54:3408-16.

Nanki T, Imai T, Nagasaka K, et al. 2002. Migration of CX3CR1-positive $\mathrm{T}$ cells producing type 1 cytokines and cytotoxic molecules into the synovium of patients with rheumatoid arthritis. Arthritis Rheum, 46:2878-83.

Paludan SR. 2000. Synergistic action of pro-inflammatory agents: cellular and molecular aspects. $J$ Leukoc Biol, 67:18-25.

Ruth JH, Volin MV, Haines GK, 3rd, et al. 2001. Fractalkine, a novel chemokine in rheumatoid arthritis and in rat adjuvant-induced arthritis. Arthritis Rheum, 44:1568-81.

Shinoda K, Sugiyama E, Taki H, et al. 2003. Resting T cells negatively regulate osteoclast generation from peripheral blood monocytes. Bone, 33:711-20.

Shulby SA, Dolloff NG, Stearns ME, et al. 2004. CX3CR1-fractalkine expression regulates cellular mechanisms involved in adhesion, migration, and survival of human prostate cancer cells. Cancer Res, 64:4693-8.

Tak PP and Bresnihan B. 2000. The pathogenesis and prevention of joint damage in rheumatoid arthritis: Advances from synovial biopsy and tissue analysis. Arthritis Rheum, 43:2619-33.

Takayanagi H, Sato K, Takaoka A, et al. 2005. Interplay between interferon and other cytokine systems in bone metabolism. Immunol Rev, 208:181-93.

Takeshita A, Chen Y, Watanabe A, et al. 1995. TGF-beta induces expression of monocyte chemoattractant JE/monocyte chemoattractant protein 1 via transcriptional factor AP-1 induced by protein kinase in osteoblastic cells. J Immunol, 155:419-26.

Udagawa N, Kotake S, Kamatani N, et al. 2002. The molecular mechanism of osteoclastogenesis in rheumatoid arthritis. Arthritis Res, 4:281-9.

Umehara H, Bloom E, Okazaki T, et al. 2001. Fractalkine and vascular injury. Trends Immunol, 22:602-7.

van Roon JA, van Roy JL, Duits A, et al. 1995. Proinflammatory cytokine production and cartilage damage due to rheumatoid synovial T helper-1 activation is inhibited by interleukin-4. Ann Rheum Dis, 54:836-40

Volin MV, Woods JM, Amin MA, et al. 2001. Fractalkine: a novel angiogenic chemokine in rheumatoid arthritis. Am J Pathol, 159:1521-30.

Wang F, Sengupta TK, Zhong Z, et al. 1995. Regulation of the balance of cytokine production and the signal transducer and activator of transcription (STAT) transcription factor activity by cytokines and inflammatory synovial fluids. $J$ Exp Med, 182:1825-31.

Yajima N, Kasama T, Isozaki T, et al. 2005. Elevated levels of soluble fractalkine in active systemic lupus erythematosus: Potential involvement in neuropsychiatric manifestations. Arthritis Rheum, 52:1670-5.

Yoshida H, Imaizumi T, Fujimoto K, et al. 2001. Synergistic stimulation, by tumor necrosis factor-alpha and interferon-gamma, of fractalkine expression in human astrocytes. Neurosci Lett, 303:132-6.

Zhu JF, Valente AJ, Lorenzo JA, et al. 1994. Expression of monocyte chemoattractant protein 1 in human osteoblastic cells stimulated by proinflammatory mediators. J Bone Miner Res, 9:1123-30. 